\title{
Emphysema: Imaging for Endoscopic Lung Volume Reduction
}

\section{Lungenemphysem: Bildgebung bei endoskopischer Lungenvolumenreduktion}

Authors

Affiliations
B. Storbeck' ${ }^{1}$, T. H. Schröder ${ }^{2}$, M. Oldigs ${ }^{3}$, K. F. Rabe ${ }^{3}$, C. Weber ${ }^{2,4}$

Affiliation addresses are listed at the end of the article.

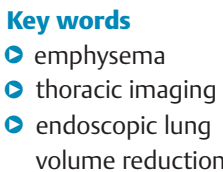

volume reduction received 29.7.2014

accepted 26.2.2015

Bibliography

DOI http://dx.doi.org/

10.1055/s-0034-1399424

Published online: 21.4 .2015

Fortschr Röntgenstr 2015; 187:

543-554 @ Georg Thieme

Verlag KG Stuttgart · New York .

ISSN 1438-9029

\section{Correspondence \\ Dr. Barbara Storbeck}

Department of Radiology,

LungenClinic Großhansdorf

Woehrendamm 80

22927 Großhansdorf

Germany

Tel.: ++49/41 02/6016781

Fax: ++ 49/41 02/691317

b.storbeck@lungenclinic.de

\section{Abstract \\ $\nabla$}

Chronic obstructive pulmonary disease (COPD) is characterized by two entities, the more airway-predominant type ("bronchitis") on the one hand, and emphysema-predominant type on the other. Imaging via high-resolution computed tomography plays an important role in phenotyping COPD. For patients with advanced lung emphysema, new endoscopic lung volume reduction therapies (ELVR) have been developed. Proper selection of suitable patients requires thinsection reconstruction of volumetric $\mathrm{CT}$ image data sets also in coronal and sagittal orientation are required. In the current manuscript we will describe emphysema subtypes (centrilobular, paraseptal, panlobular), options for quantifying emphysema and this importance of regional distribution (homogeneous or heterogeneous, target area) as this is crucial for patient selection. Analysis of the interlobular fissures is obligatory despite the lack of standardization, as incomplete fissures indicate collateral ventilation $(\mathrm{CV})$ via parenchymal bridges, which is an important criterion in choosing endoscopic methods of LVR. Every radiologist should be familiar with modern LVR therapies such as valves and coils, and furthermore should know what a lung doctor expects from radiologic evaluation (before and after ELVR). Finally we present a checklist as a quick reference for all steps concerning imaging for ELVR.

Key points:

- High-resolution computed tomography with $3 \mathrm{D}$ reconstructions becomes increasingly important in phenotyping COPD and diagnosing emphysema.

- Patient selection is crucial for modern techniques of lung volume reduction, such as valves or coils.
- Radiology plays a key role for fissural analysis and identifying a target area.

- Success of this therapy depends on experience and multidisciplinary cooperation. Citation Format:

- Storbeck B, Schröder TH, Oldigs M et al. Emphysema: Imaging for Endoscopic Lung Volume Reduction. Fortschr Röntgenstr 2015; 187: $543-554$

\section{Zusammenfassung \\ $\nabla$}

Die Chronisch Obstruktive Lungenerkrankung (COPD) ist eine Erkrankung mit zwei verschiedenen Ausprägungsarten, dem eher atemwegdominierten Typ („Bronchitis“) und dem emphysemdominierten Typ. Für die Phänotypisierung spielt die Bildgebung mittels hochauflösender Computertomografie eine wichtige Rolle. Im Falle eines fortgeschrittenen Emphysems bestehen neue zielgerichtete endoskopische Verfahren zur Lungenvolumenreduktion (ELVR). Zur Prüfung der Indikation ist die Erhebung von Volumendatensätzen nötig, die dünne Rekonstruktionen auch in koronarer und sagittaler Schnittführung ermöglichen. Im Folgenden werden neben der Differenzierung zwischen den verschiedenen Emphysemarten (zentrilobulär, panlobulär, paraseptal) auch die Möglichkeiten der Quantifizierung und die Bedeutung der regionalen Emphysemverteilung (homogen oder heterogen, Zielareal) für die Patientenselektion erläutert. Die Analyse der interlobären Fissuren ist trotz bislang fehlender Standardisierung obligat, da bei inkompletten Fissuren von einer Kollateralventilation (CV) über Parenchymbrücken auszugehen ist, einem wichtigen Kriterium für die Auswahl des Verfahrens. Jeder Radiologe sollte die modernen Verfahren der LVR wie Ventile oder Coils kennen und wissen, welche radiologischen Informationen der Pneumologe vor und 
nach der Anwendung der ELVR benötigt. Dazu wurde zusammenfassend eine Checkliste für die radiologische Emphysemdiagnostik erstellt.

\section{Introduction}

$\nabla$

Chronic obstructive pulmonary disease (COPD) is one of the most common diseases worldwide, having a prevalence of approximately $9 \%$ in Germany [1]. The disease is diagnosed according to clinical and functional findings, and classified by severity (GOLD stage $1-4$ ) and into groups according to GOLD guidelines [2].

Even patients with similar degrees of impaired pulmonary function yield completely different morphological pictures through radiological imaging, both in terms of the extent ("quantifying") and the prevailing type of morphological changes ("qualifying"). Distinctions must be made between emphysema- and airway-predominant "phenotype", with classification being made with the aid of computed tomography [3-6]. Imaging diagnostics have become increasingly relevant in recent years, since different strategies exist for the two patient groups which open new perspectives particularly for the emphysema group.

Modern emphysema therapy includes, above all, endoscopic lung volume reduction methods (ELVR). In particular, valves and coils are seeing increased use, thus requiring radiologists to become familiar with the different methods and diagnostic criteria.

\section{Phenotyping COPD: Emphysema? \\ $\nabla$}

The severity and course of COPD is determined by gathering the patient's history and testing lung function. Important parameters are forced exhalation (FEV1, forced expiratory volume in one second), FEV1/FVC quotient (Tiffeneau index) and diffusion capacity. The ITGV (intrathoracic gas volume) with RV (residual volume) and TLC (total lung capacity) are used to detect hyperinflation. To ascertain their normal routine physical capacity, patients undergo a standardized 6-minute walking test.

Severity staging according to GOLD is founded on the FEV1 limitation based on values following bronchodilation (GOLD 1 FEV $1 \geq 80 \%$, GOLD 2 FEV $1<80 \% \geq 50 \%$, GOLD 3 FEV $1<50 \%$ $\geq 30 \%$, GOLD $4<30 \%$ of target). Patients are can additionally be classified into groups A through $\mathrm{D}$ according to symp- toms and exacerbations per year. However, the morphological information indicating whether emphysema is present and, if so, to what extent and how it is distributed can be obtained only through medical imaging. According to the EvA study, it is possible to classify cases as E- (emphysema) or A- (airway disease) type by measuring lung density and bronchial wall thickness [7], most cases being a mixed picture with varying degrees of both components.

\section{Airway type}

The chronic inflammatory process reshapes the major and minor airways.

The bronchial walls become thicker (chronic bronchitis) and either narrow (obstruction) or widen (bronchiectasis), while the airways become unstable.

When the minor airways are involved (small airway disease), indirect and direct signs of bronchiolitis are present. In the case of inflammatory (exudative, intraluminal) bronchiolitis with thickening of the bronchiolar wall and displacement of the lumen by secretion, centrilobular, micronodular densifications, which have the appearance of buds on a branch (Tree-in-bud phenomenon) appear as direct signs. With constructive, obliterative bronchiolitis, the minor airways are obstructed, the lumen of the bronchioles collapse upon expiration and air can no longer be expelled (air trapping). This is more clearly visible on expiration images when mosaic-like hypodense areas with trapped air remain (indirect sign), while normally the density increases in healthy lung parenchyma during exhalation. Comparison of inspiratory and expiratory images additionally provides information on the stability of the tracheobronchial system.

\section{Emphysema type}

Emphysema is a morphological-structural diagnosis defined as irreversible expansion of the air spaces distal to the terminal bronchioles with destruction of the walls of the affected alveoli, but without any scarring ( $\bullet$ Fig.1). Lung performance declines as a result of a loss of gas exchange surface as well as a progressive hyperinflation. LVR measures can be used only for patients suffering from an advanced stage (GOLD III through IV) depending on the type, extent and distribution of their emphysema. It is therefore necessary to first address the classification and subtypes of emphysema.
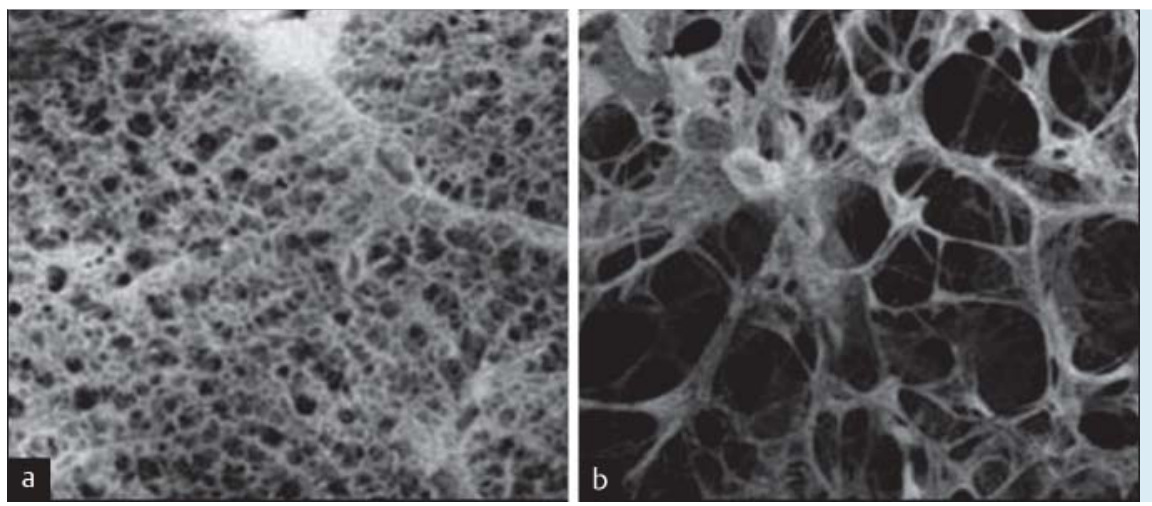

Fig. 1 Healthy $\mathbf{a}$ and abnormal $\mathbf{b}$ alveoli on an electron microscopic image. Emphysema (on the right) leads to irreversible destruction of the alveolar walls, which results in a reduced area for gas exchange. (Courtesy of PulmonX). 


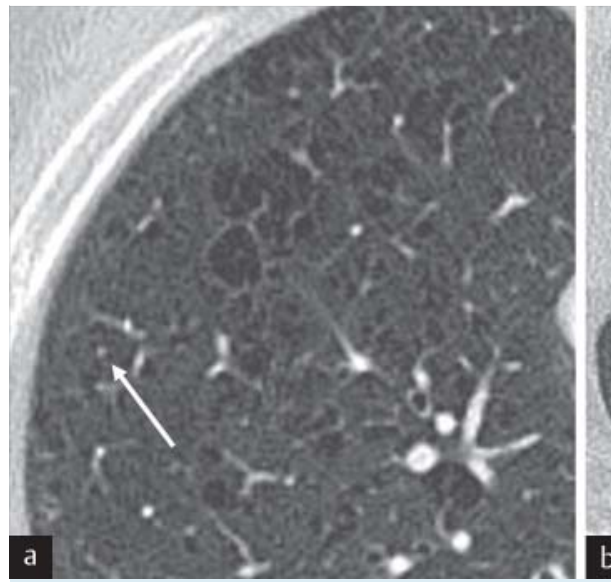

Fig. 2 Types of emphysema in relation to the secondary pulmonary lobule (HRCT sections). a Centrilobular emphysema (CLE). The process starts centrilobular with small focal lucencies without visible walls. The polygonal shape of some totally affected secondary lobules is clearly visible. The artery is seen as a white dot in the center (arrow). The interlobular septa build the margins containing pulmonary veins and lymphatics. $\mathbf{b}$ Paraseptal emphysema (PSE). Pulmonary lobules are affected peripheral, paraseptal and sub-

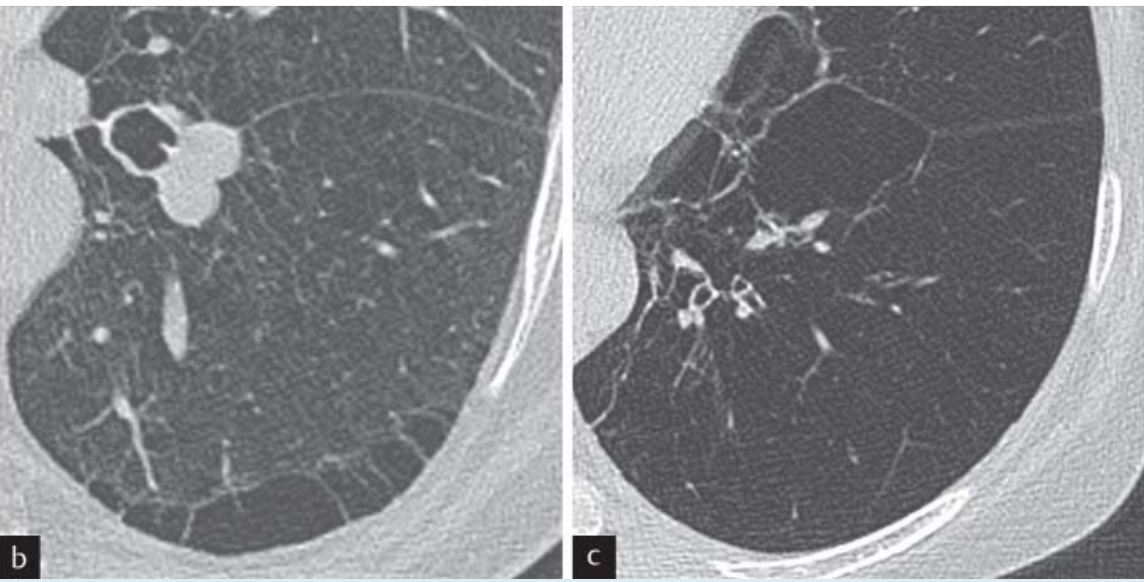

pleural. There are lucencies in a single layer with focal hyperinflation, in this case subpleural along the dorsal circumference. c Panlobular emphysema (PLE) due to alpha-1-antitrypsin deficiency. This type is characterized by uniform destruction of the entire pulmonary lobule with homogenous involvement of large parts of the lungs, mainly lower lobes. Normal parenchyma is barely visible, vessels are rarefied, lung is hyperinflated.

\section{Radiological classification of emphysema \\ $\boldsymbol{V}$}

\section{Anatomy}

Emphysema is classified based on distribution within the secondary lobule, the smallest connective tissue anatomical subunit in the lungs. The lobule is polygonal in shape, measuring approximately $1-2.5 \mathrm{~cm}$ and is surrounded by connective tissue (interlobular) septa [8]. Under normal, healthy conditions, the lobule can only be detected on CT through inference. Running through the center of the lobule are the artery and the accompanying bronchiolus. Each lobule comprises on average 12 acini, each acinus in turn containing roughly 200 alveoli. While terms lobular and acinar are often used synonymously in describing a type of emphysema, the reference to the lobule is more appropriate from a radiological viewpoint, since only this part is visible. There are three main types of emphysema [9, 10]: centrilobular, paraseptal (formally known as distal acinar) and panlobular emphysema ( $\bullet$ Fig. 2). The Fleischner Society is currently developing a new method of classifying emphysema based on severity [11]. While further descriptive terms exist, they do not constitute unique subtypes: the (large) bullous emphysema, scar emphysema (vicarious emphysema) and a compensatory overexpansion emphysema (e.g. following contralateral pneumonectomy). The term "elderly emphysema" is considered to be obsolete and should not be used to describe the physiological alveolar hyperinflation not involving destruction in the senile lung [12].

\section{Centrilobular emphysema}

Centrilobular emphysema (CLE, adopted from the Fleischner Society) is the most common type. It appears mainly in smokers, affecting primarily the superior lobe. The process begins in the center of the secondary lobule. On CT images it morphologically appears as round density reductions without a wall that look like small "holes" in the surrounding initially still healthy lung parenchyma. This finding progresses toward the periphery until the entire secondary lobule is involved. In advanced cases, multiple lobules are affected, which can progress to confluent involvement of the entire lobe and extensive parenchymal destruction ( $\bullet$ Fig. 3 ).

\section{Paraseptal emphysema}

With paraseptal emphysema (PSE) the peripheral, subpleural lobules are selectively affected. Density reductions and hyperinflations are visible along the pleura. The superior lobes are affected above all, e.g. resulting from scarring post-infectious shrinkage processes. This type of emphysema appears even in young nonsmokers and is frequently the cause of spontaneous pneumothorax.

\section{Panlobular emphysema}

Panlobular emphysema (PLE) is typical in patients with alpha- 1 antitrypsin deficiency and the term is reserved for this condition (for cases of advanced, originally centrilobular emphysema, the term confluent emphysema is more appropriate)

The entire lobule exhibits relatively homogeneous, panlobular destruction. In this context, the "pan" refers to the secondary lobule (pan-lobular) not to the lobe. This is important to note, since the terms lobule (the small subunit) and lobe (the pulmonary lobe) should not be confused in everyday clinical activity. The lobules are inflated and the blood vessels rarefied. Distribution within the lobes is not localized or focal, but rather uniform and usually extensive. It is the inferior lobes that are primarily affected.

\section{Bulla}

A bulla is a sharply demarcated air-filled lesion greater than one centimeter in diameter (smaller lesions are called "blebs" = bubbles) with a delicate wall measuring less than one millimeter thick [13]. The disease is referred to as bullous emphysema when bullae are prominent. Giant bullae can measure more than $10 \mathrm{~cm}$ and take up a large volume, while compressing the surrounding lung parenchyma. 

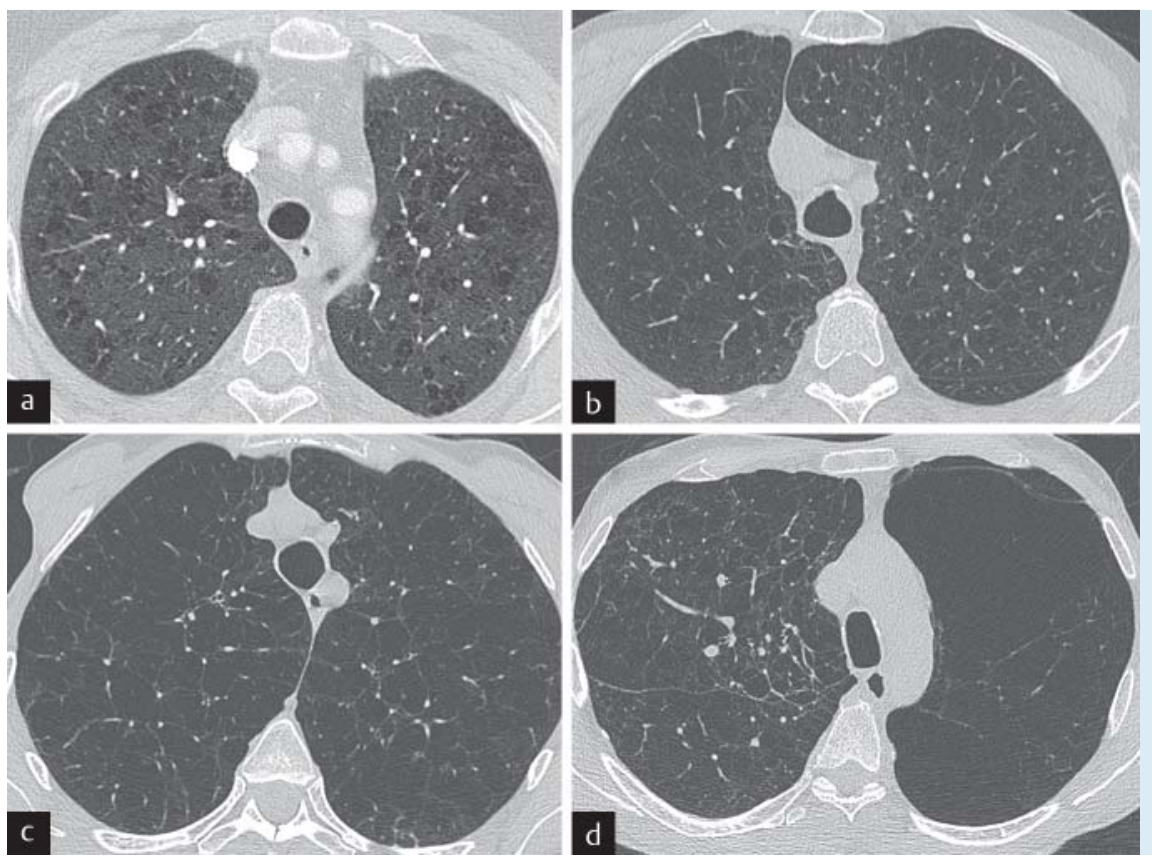

Fig. 3 Centrilobular emphysema of various severities. a Mild, with some small spotty centrilobular areas of emphysema, about 0.5 to $5 \%$ of the upper lobe, surrounded by normal parenchyma. b Moderate, with less affected regions scattered next to larger areas of destruction. c Confluent, with centrilobular and lobular parts, without relevant hyperexpansion, or destruction of the lung architecture. d Advanced destructive emphysema with marked hyperextension and destruction of the lung anatomy not caused by alpha-1-antitrypsin deficiency (derived from Fleischner Society).

\section{What every radiologist should know about emphysema therapy \\ $\nabla$}

Standard therapy for COPD, comprises, in addition to strict smoking cessation, medications such as bronchodilators and, if necessary, steroids, physical therapy, rehabilitation measures, later long-term oxygen therapy and, if necessary, non-invasive ventilation. However, the lung tissue already transformed by emphysema is irreversibly damaged. Due to the absent gas exchange surface and progressive dynamic pulmonary hyperinflation, patients in advanced stages suffer from serious dyspnea even under the most minor physical strain. In addition there are various (above all cardiovascular) comorbidities. Only after maximum conservative therapy has been exhausted, is a lung volume reduction (LVR) discussed as final stage therapy.

\section{Principle of lung volume reduction}

The idea of LVR, according to which the non-functional or pathologically hyperinflated "bloated" portions of the lung are (surgically removed) or deactivated, has existed as form of emphysema therapy for years. The objective is to achieve decompression to restore breathing space for the less affected portions of the lungs. The flattened diaphragm, which has been pressed downward, can recover and regain its rounded form. Breathing mechanics are boosted, the elastic resilience of the lungs improved and dyspnea decreased.

\section{Surgical LVR}

Surgical LVR was performed as early as the $1950 \mathrm{~s}$. At that time, the surgery was in no way equivalent to a simple bullectomy. The high peri- and postoperative mortality initially prevented the procedure from becoming established. However, it became the subject of research once again in the $1990 \mathrm{~s}$. The NETT study compared bilateral surgical LVR (usually performed by means of median sternotomy) with drug therapy between populations of 608 and 610 patients, respectively [14]. The 90-day mortality rate for the surgical group was clearly elevated at $7.9 \%$ versus $1.3 \%$, especially in cases of homogenous emphysema and forced exhalation (FEV1) values below $20 \%$ of the target. On the other hand, the patients with superior lobe emphysema and not capable of performing physical exercise benefited.

Subsequently developed minimally invasive, bronchoscopic LVR approaches are currently the subject of intensive study and examination [15-17]. In the wake of encouraging results, focus has shifted back to surgical treatment of emphysema (LVRS, lung volume reduction surgery) following years of restrained use.

Video-assisted thoracoscopic surgery (VATS) and median sternotomy exhibit comparable efficacy and safety, while involving a shorter hospital stay than VATS [18]. Study approaches are "staged VATS" (in which both side undergo two consecutive unilateral surgical interventions), a "nonresectional" LVR (clamping without actual resection of lung tissue) or laser resection. Thus far, no results are available for direct comparison between LVRS and endoscopic LVR, and the significance of LVRS is currently not clearly defined.

\section{Endoscopic lung volume reduction (ELVR)} $\nabla$

Over the last 10 years different bronchoscopic methods ( $\bullet$ Fig.4) aimed at collapsing or shrinking the emphysematous lung tissue have been developed These methods are an option only for patients with advanced stages of the disease and require an exhaustive diagnosis of lung function. Derived from the VENT-study [19], the inclusion criteria comprises, among other factors, stage 3 (through 4) COPD according to GOLD with high-grade pulmonary hyperinflation (residual volumes over $200 \%$ ). In principle, distinction must be made between blocking and non-blocking as well as between reversible and irreversible procedures. Currently established methods are compared in $\bullet$ Table 1. 

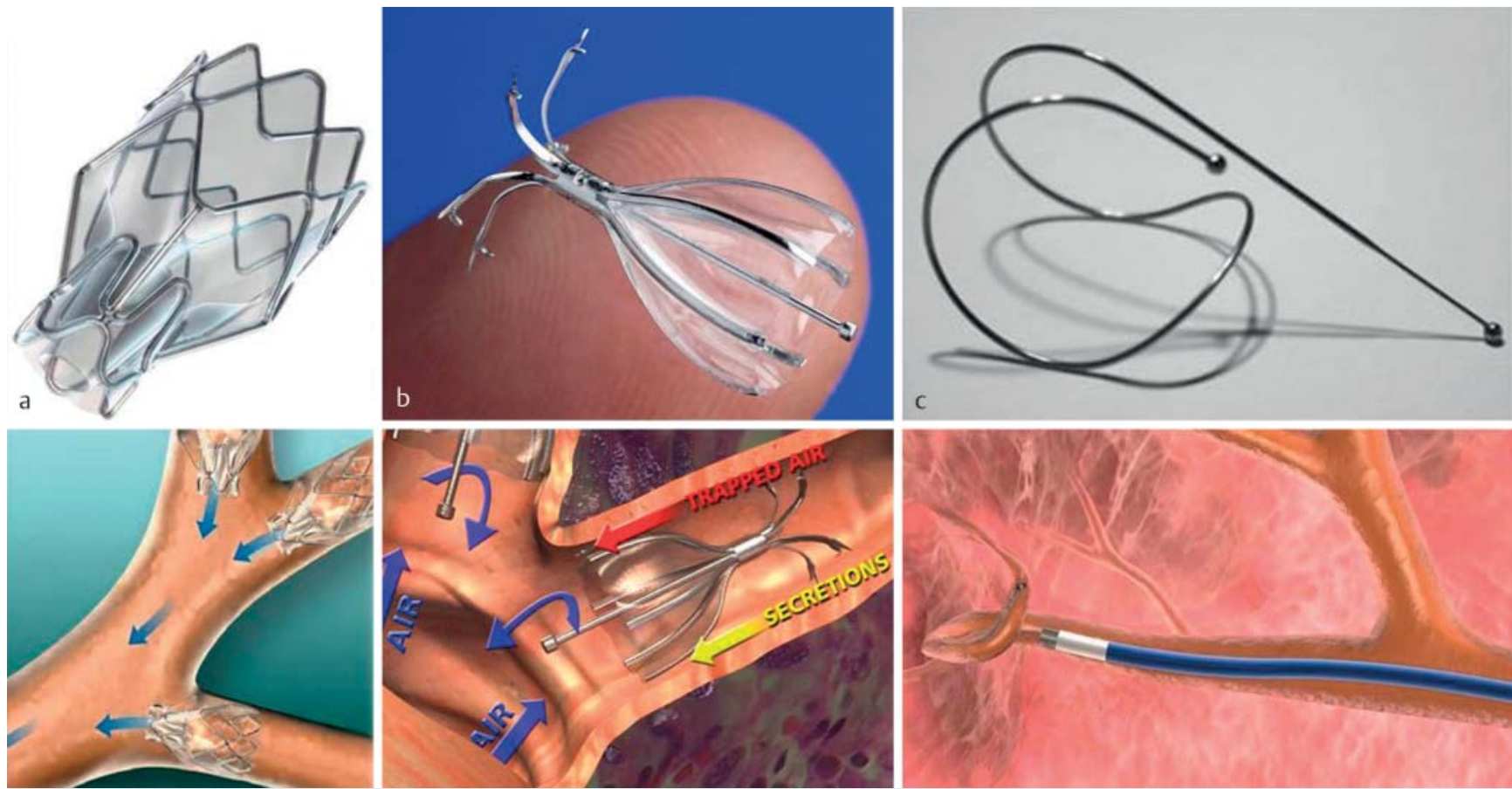

Fig. 4 Valves and coils. a Endobronchial Zephyr ${ }^{\circledR}$ valve (courtesy of PulmonX). b Intrabronchial Spiration ${ }^{\circledR}$ valve (courtesy of Olympus). c RePneu coils (courtesy of PneumRx). Bronchoscopic use is demonstrated in the bottom row.

\begin{tabular}{|lll|}
\hline & valves & coils \\
\hline technique & $\begin{array}{l}\text { one-way valves allow air to leave } \\
\text { but not enter the lung, causing } \\
\text { a collapse of the target lobe; } \\
\text { dynamic hyperinflation is reduced } \\
\text { blocking }\end{array}$ & $\begin{array}{l}\text { shape-memory coils with mechanical action } \\
\text { and tissue compression; } \\
\text { elastic recoils are restored, air trapping } \\
\text { is reduced }\end{array}$ \\
\hline $\begin{array}{l}\text { method } \\
\text { reversibility }\end{array}$ & $\begin{array}{l}\text { non-blocking } \\
\text { before ELVR }\end{array}$ & questionable \\
\hline $\begin{array}{l}\text { type of emphysema } \\
\text { heterogenous emphysema }\end{array}$ & $\begin{array}{l}\text { both heterogeneous and homogeneous } \\
\text { emphysema }\end{array}$ \\
\hline farget area & important & less important \\
\hline collateral Ventilation (CV) & integrity is crucial & not relevant \\
\hline contraindication & large parenchymal destruction & non interfering \\
\hline $\begin{array}{l}\text { after ELVR } \\
\text { atelectasis }\end{array}$ & $\begin{array}{l}\text { pulmonal hypertension, giant bullae, } \\
\text { large parenchymal destruction }\end{array}$ \\
\hline $\begin{array}{l}\text { residual parenchyma in } \\
\text { the target lobe }\end{array}$ & atelectasis should be achieved & no atelectasis \\
\hline pneumothorax & gets lost & is preserved \\
\hline hemoptysis & often & rare \\
\hline migration & possible & often \\
\hline
\end{tabular}

Table 1 ELVR-Comparison of valves and coils.

\section{Valves}

Via the working canal of a bronchoscope, multiple valves are implanted in the segmental-, if necessary subsegmental bronchi as well, of a pulmonary lobe. Placement of a valve takes only a few minutes. A valve mechanism then prevents new air from flowing into the lungs, while still allowing the "old" air to flow out, thus collapsing the pulmonary lobe ( $\bullet$ Fig. 5). The goal is complete atelectasis of the treated lobe. As of now two different types of valves for this blocking, reversible method are available on the European market.
Endobronchial valves (EBV)

EBV (Zephyr ${ }^{\circledR}$ valves from PulmonX) comprises a silicone body surrounded by a nitinol wire cage ( $\bullet$ Fig. 4a). The end pointing in the proximal direction (toward the trachea) has a narrower diameter ("neck") with a "fish mouth" valve. The initial results were published in 2003 [20]. The data of the prospective VENT study in 2006 [29] initially showed only moderate benefits. In the meantime, the critical importance of patient selection has become clear. According to the EuroVent-Study [21], predictors of successful EBV therapy 

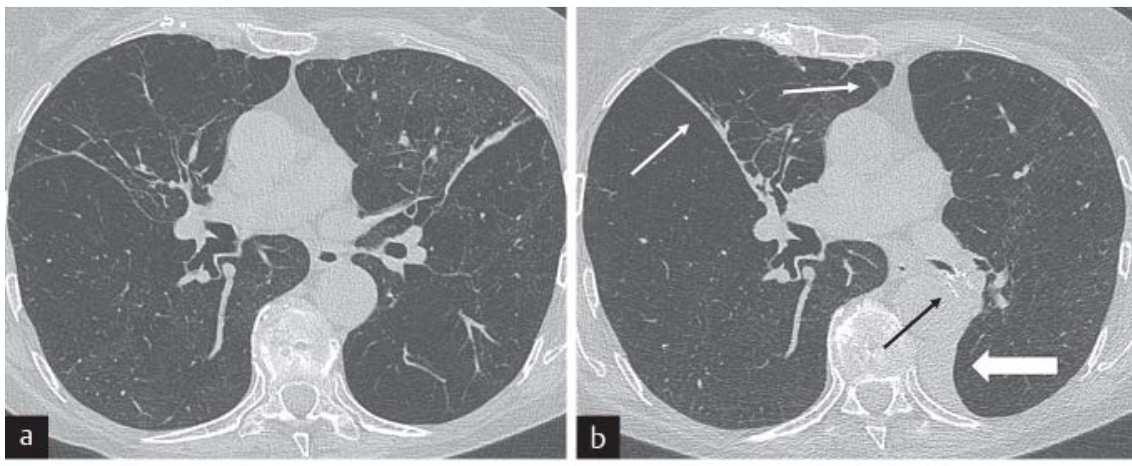

Fig. 5 Imaging before and after ELVR with valves. a HRCT before implantation of valves. $\mathbf{b}$ HRCT after implantation of valves. Afer placement of 4 valves into the left lower lobe the patient developed a lobe atelectasis as expected (thick white arrow). This section shows one of the valves in a good position with the "narrow neck" at the proximal end (black arrow). On the right side fissural and mediastinal shift is visible (thin white arrows). c Chest radiography pre-treatment (same patient). Normal middle position of the mediastinum, depression and flattening of the diaphragm. $\mathbf{d}$ Chest radiography after implantation of valves. On the left hilar region the
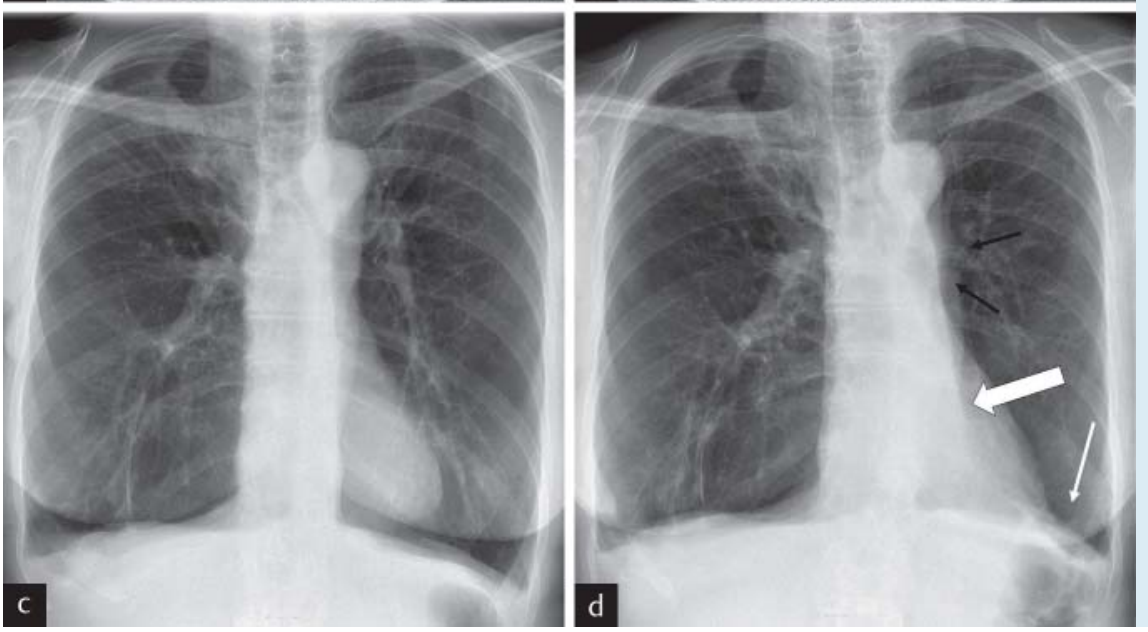

filigran mesh of the valve is hardly seen on hard copy films (black arrows) but good on monitors. Left lobe atelectasis and mediastinal shift to the left (thick white arrow). The actual level of the left hemidiaphragma is slightly more apical as a sign of reexpansion (thin white arrow).

are a heterogeneous lung emphysema, correct placement and intact fissures.

\section{Intrabronchial valves (IBV)}

IBV (Spiration ${ }^{\circledR}$ valves from Olympus) resemble small umbrellas ( $\bullet$ Fig. 4b). They are anchored via the distal feet ("anchoring hooks"), and the leaves attach to the walls of the bronchia. At the proximal end is a type of "stem" by which the valve can be gasped for removal if necessary. The unilateral complete occlusion of a lobe appears to be superior to a bilateral only partial occlusion [22].

According to user instructions, both types of valves are conditionally safe with MRI, i.e. a patient with this implant can safely undergo an MRI examination with a static magnetic field up to 3 Tesla $[23,24]$.

\section{Metal spirals, "coils"}

Wire spirals made of nitinol (a biocompatible nickel/titanium alloy) with a shape memory (RePneu ${ }^{\circledR}$ Coils from PneumRx) are used ( $\bullet$ Fig. 4c). With the aid of a special implantation system, the wires measuring roughly 10 to $15 \mathrm{~cm}$ long are first introduced into the segmental bronchia under fluoroscopy, usually 10 units (if necessary more) being implanted in the selected lobes. Upon being released, the wires resume their original spiral shape ( $\bullet$ Fig. 6 ), thereby pulling the bronchia together with the lung tissue to the hilum through mechanical force. A certain compression of the pulmonary parenchyma is achieved, the actual goal being the improvement of the elastic restoring forces. These nonblocking, debatably reversible methods do not result in atelectasis. The latest results show this method to be effective on heterogeneous and homogenous emphysema [25]. The product received the CE label in October 2010 and is MRIcompatible up to 3.0 Tesla [26].

\section{Additional methods: Vapor, gel and stents}

Other irreversible, non-blocking methods include the introduction of hot water vapor (bronchoscopic thermoablation) or hydrogel foam ("bronchial adhesives", polymer LVR or BioLVR) to systematically induce inflammatory stimulation in the most intensely affected area of the lung [27]. The goal is an acute, but "controlled" inflammatory process with subsequent shrinkage of the tissue through scarring or fibrosis. Although a meta-analysis [28] showed the best results for BioLVR, this method is currently no longer available. Thermoablation is still considered to be experimental, since there have been no major studies [29]. Endoscopic creation of artificial airways by means of needle perforations (airway bypass) has been suspended due to complications (EASE-study) [30].

\section{What pulmonologists expect from radiological imaging and reporting?}

$\nabla$

\section{$\mathrm{X}$-ray/CT/MRI?}

According to the guidelines of the German Respiratory Society (Deutschen Gesellschaft für Pneumologie), a chest Xray in two views should be performed for general diagnostics when COPD is initially diagnosed. The validity of the criteria for emphysema already defined in 1965 was confirmed once again by Miniati et al. 2008 [31]. We routinely see flat, low-lying diaphragmatic arches, increased lung transparency, and enlarged retrosternal space as well as ex- 


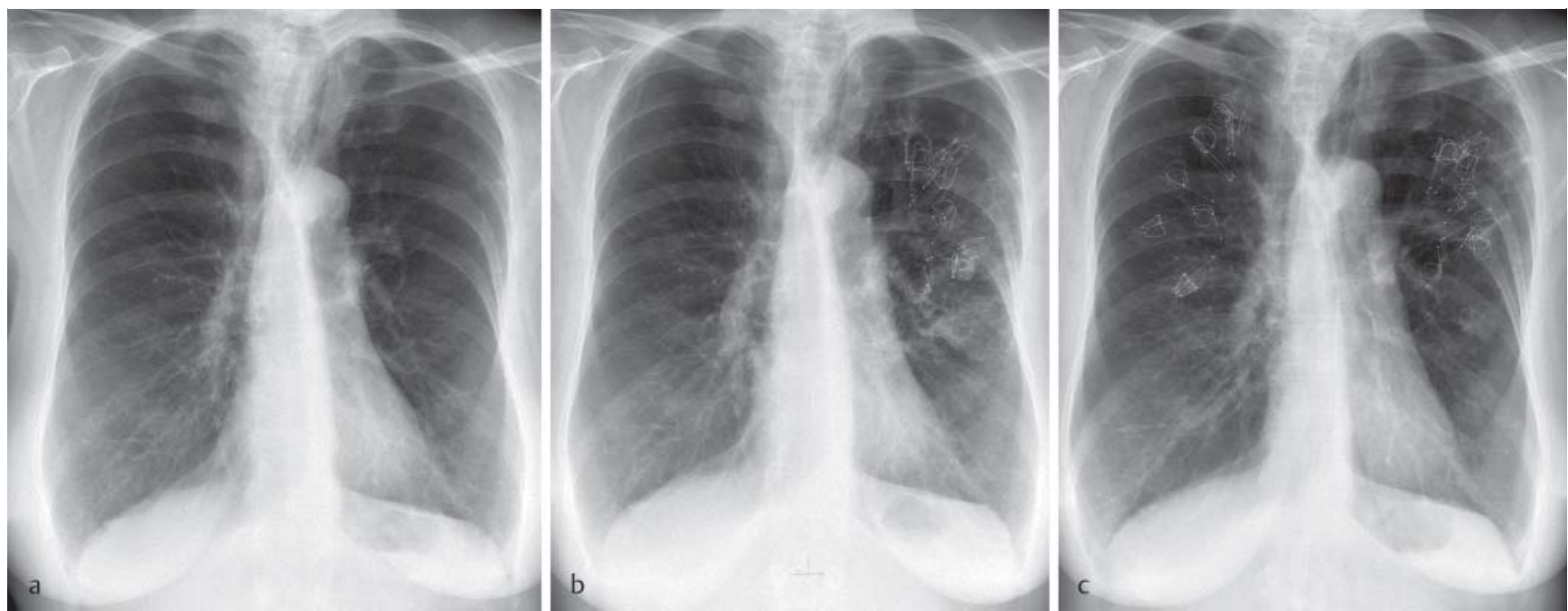

Fig. 6 Chest radiography before and after ELVR with coils. a Pre-ELVR. b After treatment with coils in the left superior lobe. c After treatment with coils in the superior lobes, bilateral.

panded intercostal spaces, a barrel chest and, as the case may be, a teardrop-shaped, narrow heart silhouette. However, when dealing with mild forms of emphysema, this method is not sufficient for determining distribution and is in no way suited for testing whether ELVR is indicated.

The lungs present a challenge for MRI, since they have a very low proton density compared to the brain, liver or musculature, and the margins between the air and parenchyma lead to susceptibility artifacts. Breathing and heartbeat additionally create motion artifacts, thereby necessitating rapid sequences, parallel imaging as well as breathing and EKG triggering [32]. In the majority of cases, there is agreement between MRI and CT in classifying emphysema and evaluating the severity thereof [33]. On the other hand, the morphological and functional magnetic resonance imaging of COPD with visualization of ventilation, breathing dynamics and perfusion is becoming increasingly prominent [34]. Dynamic MRI during continued breathing is excellent at showing how severely diaphragmatic mobility is restricted is cases of emphysema [35]. The phenotyping of COPD using MRI and low-dose CT is currently being compared in a multicentric, national cohort study (Cosyconet) [36]. However, the lengthy examinations and long periods of having to hold their breath still remain difficult for patients who already suffer from dyspnea due to their underlying disease.

Without a doubt, CT of the lungs is currently the method of choice. Pulmonologists expect a non-contrast, high-resolution spiral CT taken during inspiration. If disease of the minor airways is suspected, sequential scans during expiration should additionally be performed.

The technical prerequisite is a 3 rd generation or above multi-detector CT with at least 16 lines, the standard being 64lines (if necessary 40 lines). According to definition, slice thickness for a HRCT should be less than $1.5 \mathrm{~mm}$ [8]. A slice collimation below $1 \mathrm{~mm}$ (depending on manufacturer, e.g. $0.6 \mathrm{~mm}$ ) with as low of a rotation period as possible $(\leq 0.5 \mathrm{~s})$, an increment of 0.7 and an overlap of $30-50 \%$ is recommended. In CT protocols of the thorax there are considerable differences in current exposure time product
(40 mAs to $200 \mathrm{mAs}$ ) [37]. Low-dose data sets with a current exposure time product of just 30 to $50 \mathrm{mAs}$ allow both a visual and quantitative evaluation of the emphysema [38]. In contrast, a higher dosage is necessary for the analysis of the airways particularly in the case of software-assisted evaluations. For example, the median effective current exposure time product in the COPD Gene Study was $180 \mathrm{mAs}$ [39]. In our scan protocol, tube current was $100 \mathrm{mAs}$ and tube voltage $120 \mathrm{KV}$. To reduce radiation exposure, automatic dosage modulation was employed. Iterative image reconstruction techniques are also highly promising. While the image quality suffers when dosage is reduced by $50 \%$ and data sets are reconstructed by means of filtered rearprojection (for example, because of the increased noise pattern the differentiation between residual lung parenchyma and bulla was compromised), iterative reconstruction technique allows a comparable image quality to be achieved at half the radiation dose [40].

Generating sagittal and coronal $3 \mathrm{D}$ reconstructions is especially important, with reconstructed slice thickness of $\leq 1.5 \mathrm{~mm}$ also being ideal in this case. A differentiated evaluation of findings focusing on the following diagnosis- and therapy-relevant criteria is required.

\section{Quantification of the emphysema}

In routine clinical practice, the individual patient's complaints do not accurately foreshadow the morphology or severity of the emphysema revealed through $\mathrm{CT}$, although the extent of the emphysema correlates with the severity of COPD at least in cases of centrilobular and panlobular, but not paraseptal type. In addition to the purely quantitative description in the report, an assessment that is as standardized, objective and reproducible to the extent possible is required. Lung density measurements using Hounsfield units (HU) and an estimate of the extent of emphysema as a percentage (e.g. $0 \%$, below $5 \%$, up to $25 \%$, up to $50 \%$, up to $75 \%$, over $75 \%$ ) are helpful in this respect [42]. Visual assessment is performed separately for the individual lobes of the lungs. The examiner-dependent variability remains problematic [41-43]. 

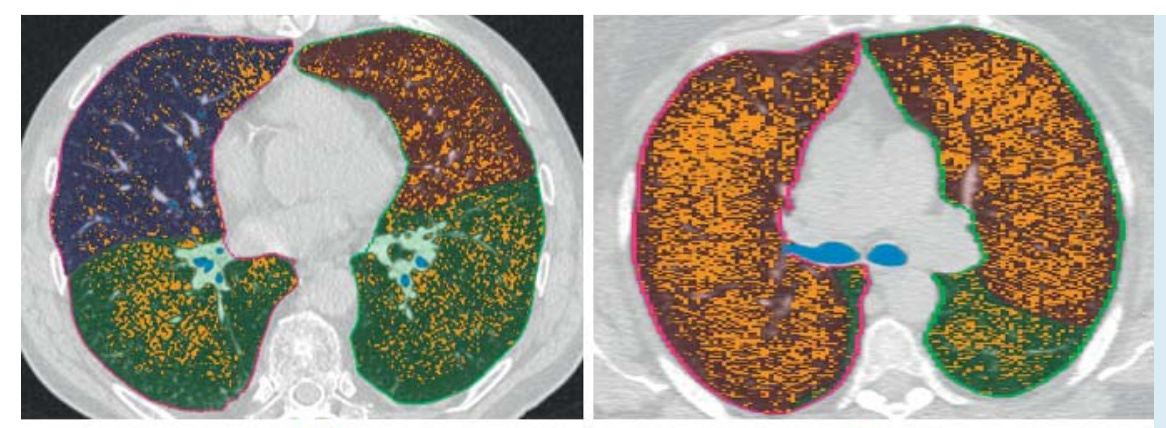

Fig.7 Software analysis of emphysema. Areas with low attenuation are depicted in orange indicating centrilobular emphysema. Upper image shows axial HRCT scan, 3D-rendering is seen in lower image. a Heterogeneous distribution, all lobes are affected, no explicit predominance. $\mathbf{b}$ Marked predominance of emphysematous regions in both upper lobes, possible target areas for ELVR. (Courtesy of Fraunhofer MEVIS, Bremen).
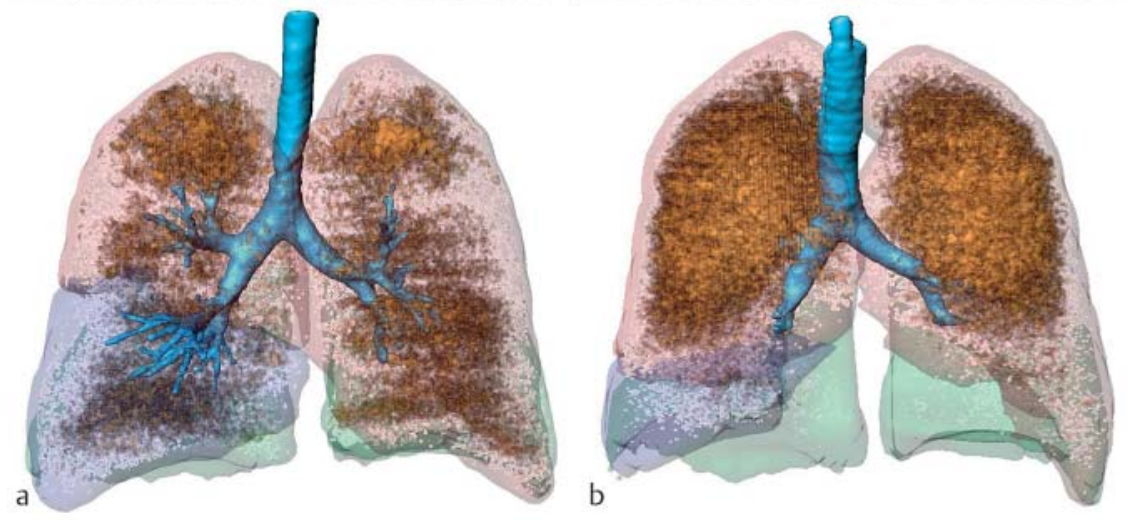

CT-densitometry can be performed semiquantitatively or quantitatively (computer-assisted) [44]. Evaluation is reportedly made easier with specialized software which shows emphysematous areas marked in color (e.g. as color map) on the basis of a prescribed density limit value and generates a table summarizing density values. The average lung density (expressed in HU) can be computed from the density values of all lung voxels, while segmentation of the lung margins is fully automatic. The emphysema index can be computed as a quotient of emphysema volume and lung volume (expressed in percent). Several programs are already commercially available ( $\bullet$ Fig. 7 ). However, there are major differences in the different types of software, among which are the evaluation and presentation of data. While the results were still disappointing in 2006, e. g. the considerable amount of time required and the poor correlation between human eyes and the machine [45], by 2014 it was more than clear that qMDCT (CT densitometry using multidetector-row computed tomography) represents a diagnostic gain [46]. However, it remains unclear how strongly patient-related factors (age, inspiration depth) influence the measured values. In addition, a uniform threshold value for density measurement has not yet been established (initially -910 HU, then -970 HU, now usually -950 HU) [47]. Moreover, the computer-based segmentation of the individual lobes of the lung is still not reliable [48], and areas with increased density such as dystelectases and infiltrates are problematic. Serious differences in terms of evaluation appear depending on the CT scanner used, the reconstruction parameters and, above all, the software manufacturer [48]. The indication of the "PD 15" value - the lung density of the 15th percentile when showing the relative frequency of all measured voxel densities in a histogram - is highly promising. With emphysema, the low density values shift the HU distribution curve to the left and into the negative region. The EXACTLE study examining alpha-1 antitrypsin defi- ciency demonstrated that CT densitometry can represent a valid endpoint in a longitudinal study [49]. Unfortunately, no broadly available, reproducible standard has yet been established for software-based diagnosing of emphysema.

\section{Target area}

Only with the aid of radiology can the distribution of emphysema and the heterogeneity thereof be evaluated. A multidisciplinary approach must be employed to determine whether or not a target area exists. Emphysema being prominent in a lobe of the lung with hyperinflation or disproportionately high volume, e.g. visible in the form of a displacement of the lobe fissures and mediastinum, would be ideal. In contrast, giant bullae or an excessively extensive destruction of the parenchyma if anything impede endoscopic measures, since the presence of consecutively larger hollow spaces poses the risk of uncontrolled tissue tearing. The quantity and quality of the residual parenchyma are not irrelevant. The idea behind the valves is to remove all air from the target lobes and achieve atelectasis of a lobe to reduce as much volume as possible. In this process, however, the lobe is completely "deactivated", and its remaining parenchyma is no longer available for gas exchange. With the coils, in contrast, the residual tissue is "preserved" and can continue to function for gas exchange, since the target lobe remains ventilated. In cases of homogenously distributed emphysema, valves are at least not recommended. In addition, pre-interventional lung perfusion scintigraphy is recommended for estimating the loss of function following treatment of the target area. MRI of lung perfusion can also be expediently used to diagnose diseases of the airways and lung parenchyma [50]. For planning LVR, the areas of the lungs with impaired function can be visualized with the advantage of higher spatial resolution, combined imaging of morphology and function as well as absence of ra- 


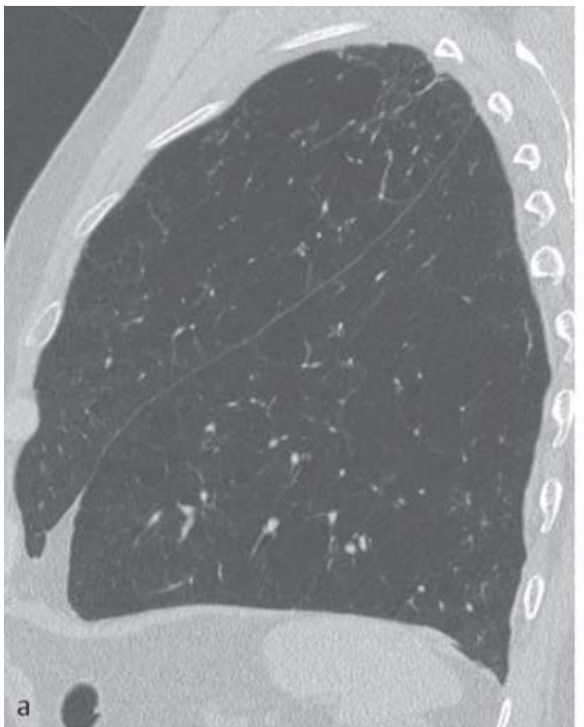

Fig. 8 Fissural analysis as a selection criterion for ELVR (HRCT, sagittal reconstruction). a Complete fissure. Visualization of the interlobular fissure as a contiguous sharp fine line, no obvious parenchymal bridges between superior and inferior lobe, thus no clear sign for collateral ventilation in this section. $\mathbf{b}$ Incomplete fissure. The fine interlobular line is disrupted in the apical portions. The course of the fissure is no longer visible (arrow). Broad

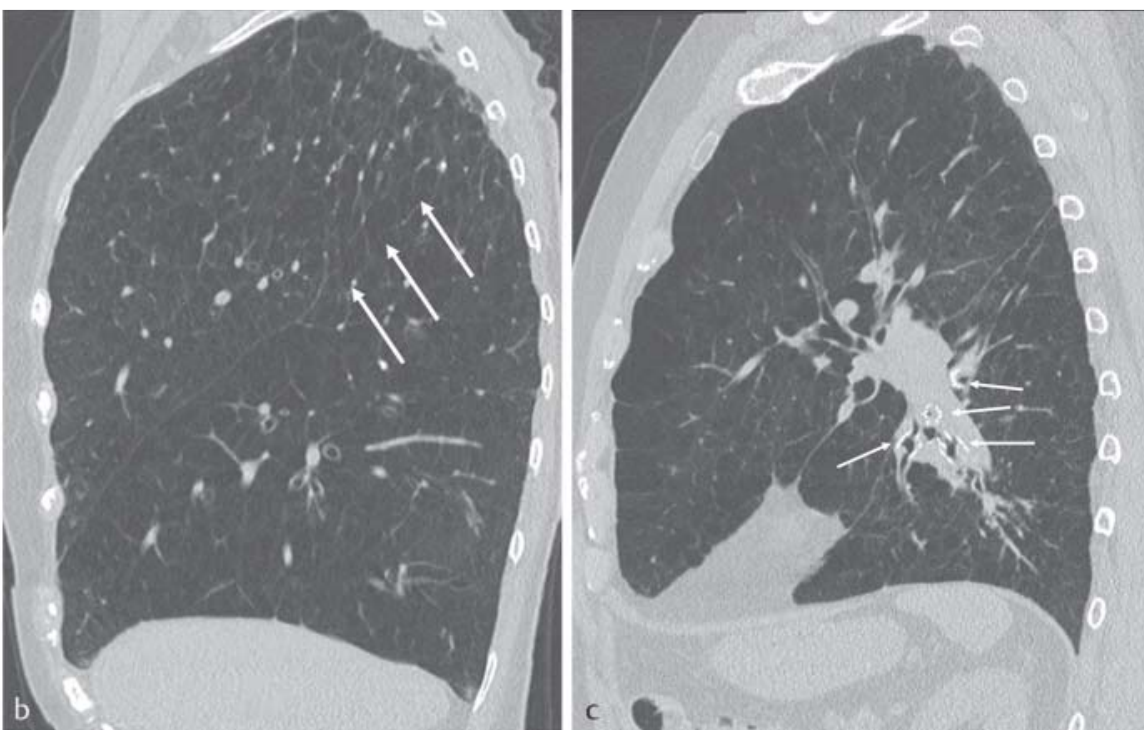

parenchymal bridges between upper lobe and inferior lobe, collateral ventilation is very likely. c Absent atelectasis after ELVR. Five endobronchial valves were implanted in the left inferior lobe. In this CT scan four of them are visible (arrows). A complete atelectasis of the inferior lobe was not achieved, probable retrograde ventilation due to collateral ventilation. diation exposure. As a result, this method can also be used to assess the course of the disease following LVR.

\section{Fissure analysis: The interlobular fissures}

CT examinations performed following valve implantations have shown that the desired atelectasis is frequently not achieved, can have a delayed onset or is only temporary [51]. The main reason for this would be what is referred to as collateral ventilation (CV), i.e. even if the valves are placed correctly and good occlusion is established, a retrograde reventilation of the treated lobe occurs via parenchymal bridges from the neighboring lobe [52]. This process hinders the actual value reduction. It is now known that $\mathrm{CV}$ is an important selection criterion. Radiology provides answers by allowing analysis of the interlobular fissures (ه Fig. 8). A normal left lung has only one fissure, while the right has an oblique fissure (lower fissure) and horizontal fissure (upper fissure, running horizontally between the superior lobe and middle lobe). Visualizing the pulmonary fissures as continuous, sharp lines requires a collimation of 0.5 to $1.0 \mathrm{~mm}$ [53] along with sagittal and coronal multiplanar reconstructions. A radiologically imaged continuous "complete" fissure is an indirect sign of an absent or minor CV. In a small study involving 25 patients, 20 of 21 pulmonary lobes having collateral ventilation also showed a defect in the fissure, with sensitivity being $95 \%$. However, specificity was only $44 \%$, i.e. 7 of 16 evaluated lobes without collateral ventilation had no fissure interruption on CT [54].

What constitutes a complete or incomplete fissure remains problematic, as neither has yet been uniformly defined in terms of CT morphology. As a result, the reported occurrence of incomplete fissures greatly fluctuates in the literature between $20 \%$ and $87 \%$. Automatic fissure analysis methods are currently being developed [55].
A computer-assisted analysis of 573 CT-examinations recently showed that roughly $90 \%$ of all examined persons have incomplete fissures regardless of whether COPD is present or not [56]. For the individual fissures, integrity was around $82 \%$ for the oblique fissures (bilateral) and $62 \%$ for the horizontal fissure, regardless of severity of COPD. Integrity of 90-100\% was defined as "complete" (continuous, intact fissure) and was present in only a quarter of patients, left $25 \%$, right $26 \%$ (oblique fissure) and $14 \%$ (horizontal fissure). Contradicting these findings, an analysis of 250 CT images with a by far higher portion of intact fissures showed the left fissure to be incomplete in only $24.4 \%$ of cases (thus appearing continuous in three quarters of all patients), and the right fissure incomplete in $35 \%$ of cases. [57].. There is a consensus regarding at least the horizontal fissure, which very frequently appears to be uninterrupted, as well as regarding the perihilar region, which is more difficult to evaluate and is where parenchymal bridges tend to form. The clinical significance of "small" parenchymal bridges (appearing in approximately one third of patients [58]) as well as accessory fissures (appearing in $16 \%$ of patients, primarily in the superior lobes [57]) on CV has not been clarified.

Collateral ventilation can also be measured through bronchoscopy using a balloon catheter. This can be performed in a procedure immediately prior to ELVR. A reduction of lung volume can be forecast with an accuracy of approximately $75 \%$ using the Chartis ${ }^{\circledR}$ evaluation system. However, this method does not replace CT. A prospective study is currently being conducted to determine whether the clinical benefit can be predicted when a homogenous emphysema with intact fissure is diagnosed using CT [60]. Overall, fissure analysis using CT must be viewed cautiously for the time being. In addition to a thorough scanning in all three planes, a uniform classification is urgently required 


\begin{tabular}{|c|c|c|}
\hline \multicolumn{2}{|l|}{ checkpoint } & note \\
\hline \multicolumn{2}{|l|}{ image aquisition } & $\begin{array}{l}\text { high-resolution multidetector } \mathrm{CT} \text { of the lungs without contrast } \\
\text { spiral technique, contiguous, slice thickness } 1.0 \text { to } 1.5 \mathrm{~mm} \\
3 \mathrm{D} \text { reconstructions in axial, coronal and sagittal orientation } \\
\text { submission of images via CD/DVD }\end{array}$ \\
\hline \multirow[t]{4}{*}{ phenotyping } & airway-type & bronchitis? bronchiolitis? mucus? bronchiectasis? instability of airways? \\
\hline & emphysema-typ & $\begin{array}{l}\text { centrilobular, paraseptal, panlobular } \\
\text { giant bullae? }\end{array}$ \\
\hline & & $\begin{array}{l}\text { extension: mild, moderat, confluend, large destructions } \\
\text { if available: specified as a percentage } \\
\text { if available: automatic quantitative assessment }\end{array}$ \\
\hline & & $\begin{array}{l}\text { distribution: homogeneous, heterogeneous } \\
\text { if available: heterogenity-/emphysema-index }\end{array}$ \\
\hline \multirow[t]{4}{*}{ before ELVR } & target area & yes (where?)/no \\
\hline & fissure-integrity & $\begin{array}{l}\text { major and minor fissur: contiguous line? gaps? } \\
\text { careful inspection in all directions including MPR }\end{array}$ \\
\hline & contraindications & pulmonal hypertension? pneumonia? \\
\hline & relevant pathologies & Lung cancer, pleural thickening, pleural effusion, ... \\
\hline \multirow[t]{4}{*}{ after ELVR } & ELVR-device & $\begin{array}{l}\text { valves or coils visible? } \\
\text { number of devices compliant to anamnesis? } \\
\text { implantation in correct side/ correct segment bronchi? } \\
\text { occlusion of the bronchi? migration/aspiration/dislocation? } \\
\text { correct position? EBV: narrow end ("neck") points to the proximal } \\
\text { IBV: the " } 5 \text { arm anchor tip" points to the distal } \\
\text { coils: about } 2 \mathrm{~cm} \text { distance to pleura }\end{array}$ \\
\hline & LVR-effect & $\begin{array}{l}\text { volume reduction effect? } \\
\text { atelectasis? } \\
\text { mediastinal shift? fissural shift? } \\
\text { reexpansion of the diaphragma? }\end{array}$ \\
\hline & complications? & pneumothorax? infiltration? hemorrhage? \\
\hline & new target area? & yes/No \\
\hline
\end{tabular}

Table 2 Checklist for Imaging for ELVR. for defining an intact fissure and assessing collateral ventilation.

\section{Routine clinical experiences with ELVR}

$\nabla$

For adequate treatment of emphysema, radiologists and pulmonologists must work together as a team. While careful patient selection on the basis of clinical findings and imaging is critical, it is not yet sufficiently practiced at all intuitions. In the meantime, the results following ELVR are increasingly coming to our attention in cases of, for example, valves becoming dislocated or having to become removed due to complications.

Among the frequent complications following ELVR are exacerbation of COPD and infections, including pneumonia. Caution is thus urged for patients with hypersecretory bronchitis, as the valves can be displaced by the secretion. Before undergoing ELVR, patients should be free of bronchopulmonary infection, have no serious concomitant disease and be mobile and clinically stable. The patient must also be able to tolerate a pneumothorax in the pulmonologist's medical opinion, since the occurrence thereof must be anticipated as a result of the at times enormous tractive forces following ELVR. On radiological images, these forces are indicated by post-interventional migration of the fissures and the mediastinum. Extensive tissue destruction and giant bullae can be problematic prior to ELVR, constituting a contraindication for the insertion of coils. Instead of valves, surgical LVR would be a better option to discuss. Because of the risk of bleeding, coils are also contraindicated for patients on anticoagulation therapy or suffering from pulmonary hypertension. Post-interventional hemoptysis is typical following the implantation coils, yet is usually easily managed. In addition to patient selection, good management of complications in a center is the key to success.

\section{Summary \\ $\nabla$}

Today, the implantation of valves or coils is well established at many centers. Technically relatively simple to perform, ELVR remains a purely symptomatic treatment for carefully selected advanced stage patients, which should ideally be performed at experienced centers and tracked in studies. Because the primarily promising therapy procedure prompts a lack of caution, an interdisciplinary discussion among pulmonologists, thoracic surgeons and radiologists is key for optimized patient selection. Finally, a checklist was created which is intended to aid during radiological diagnostic testing before and after ELVR ( $\bullet$ Tab. 2).

\footnotetext{
Affiliations

1 Department of Radiology, Airway Research Center North, Member of the German Center for Lung Research (DZL), LungenClinic Grosshansdorf, Germany

2 Diagnostic and Interventional Radiology, Academic Teaching Hospital of the University of Hamburg, Amalie Sieveking-Hospital, Hamburg, Germany

3 Department of Pulmonology, Airway Research Center North, Member of the German Center for Lung Research (DZL), LungenClinic Grosshansdorf, Germany

${ }^{4}$ Diagnostic and Interventional Radiology, University Medical Center Hamburg-Eppendorf, Germany
} 


\section{References}

1 Landis SH, Muellerova H, Mannino DM et al. Continuing to Confront COPD International Patient Survey: methods, COPD prevalence, and disease burden in 2012-2013. Int J Chron Obstruct Pulmon Dis 2014; 9: 597 -611. DOI: 10.2147/COPD.S61854 eCollection 2014

2 From the Global Strategy for the Diagnosis, Management and Prevention of COPD, Global Initiative for Chronic Obstructive Lung Disease (GOLD); 2014, Available from: http://www.goldcopd.org/

3 Matsuoka S, Yamahiro T, Washko GR et al. Quantitative CT assessment of chronic obstructive pulmonary disease. Radiographics 2010; 30: $55-66$

4 Xie X, de Jong $P$, Oudkerk $M$ et al. Morphological measurements in computed tomography correlate with airflow abstruction in chronic obstructive pulmonary disease: systematic review and meta-analysis. Eur Radiol 2012; 22: 2085 - 2093

5 Washko GR, Parraga G, Coxson HO. Quantitative pulmonary imaging using computed tomography and magnetic resonance imaging. Respirology 2012; 17: $432-444$

6 Coxson HO. Quantitative computed tomography assessment of airway wall dimensions: Current status and potential applications for phenotyping chronic obstructive pulmonary disease. Proc Am Thorac Soc 2008; 5: 940-945

7 Ziegler-Heitbrock L, Frankenberger M, Heimbeck I et al. The EvA study: aims and strategy. Eur Respir J 2012; 40: 823-829

8 Webb WR, Müller NL, Naidich DP. High resolution CT of the Lung. 46. Philadelphia: Lippincott Williams \& Wilkins; 2009

9 Thurlbeck WM, Müller NL. Emphysema: definition, imaging, and quantification. Am J Roentgenol 1994; 163: 1017-1025

10 Takahashi M, Fukuoka J, Nitta $\mathrm{N}$ et al. Imaging of pulmonary emphysema: a pictorial review. Int J Chron Obstruct Pulmon Dis 2008; 3: $193-204$

11 Kauczor H. Radiologische Diagnose und Therapiestratifizierung der COPD. Vortrag auf dem 95. Deutschen Röntgenkongress. Fortschr Röntgenstr 2014: 186-RKSP307_1

12 Bellia M, Benfante A, Menozzii $M$ et al. Validation of lung densitometry threshold at CT for the distinction between senile lung and emphysema in elderly subjects. Monaldi Arch Chest Dis 2011; 75: 162-166

13 Hansell DM, Bankier AA, MacMahon H et al. Fleischner Society: Glossary of Terms for Thoracic Imaging. Radiology 2008; 246: 697-722

14 National Emphysema Treatment Trial Research Group. A randomized trial comparing lung-volume-reduction surgery with medical therapy for severe emphysema. N Engl J Med 2003; 348: 239-245

15 Stanzel F. Bronchoskopische Lungenvolumenreduktion bei fortgeschrittenem Lungenemphysem: Zukunftsmusik oder viel Lärm um nichts? Pneumologie 2012; 66: 20-27

16 Gompelmann D, Eberhardt R, Herth FJ. Endoscopic lung volume reduction. A European perspective. Ann Am Thorac Soc 2013; 10: 657-666

17 Herzog D, Döllinger F, Temmesfeld-Wollbrück B et al. Interventionelle bronchologische Therapie. Eine kritische Bestandsaufnahme. Pneumologe 2014; 11: 135-143

18 Criner GJ, Cordova F, Sternberg AL et al. The National Emphysema Treatment Trial (NETT) Part II: Lessons learned about lung volume reduction surgery. Am J Respir Crit Care Med 2011; 184: 881 - 893

19 Sciurba FC, Ernst A, Herth FJ. VENT Study Research Group. et al. A randomized study of endobronchial valves for advanced emphysema. N Engl J Med 2010; 363: 1233 - 1244

20 Toma TP, Hopkinson NS, Hillier J et al. Bronchoskopic volume reduction with valve implants in patients with severe emphysema. Lancet 2003; 361: $931-933$

21 Herth FJF, Noppen M, Valipour A et al. Efficacy predictors of lung volume reduction with Zephyr ${ }^{\circledR}$ valves in a European cohort. Eur Respir J 2012; 39: 1334-1342

22 Eberhardt R, Gompelmann D, Schuhmann $M$ et al. Complete unilateral versus partial bilateral endoscopic lung volume reduction in patients with bilateral lung emphysema. Chest 2012; 142: 900-908

23 Emphasys ${ }^{\circledR}$ Zephyr ${ }^{\circledR}$. Endobronchial Valve System. Instructions for Use. http://www.fda.gov/

24 Spiration ${ }^{\circledR}$. Gebrauchsinformation Olympus. Artikelnr.: DE-61887, Version $2.0-07 / 2010$

25 Deslee G, Klooster K, Hetzel M et al. Lung volume reduction coil treatment for patients with severe emphysema: a European multicentre trial. Thorax 2014: 69980-69986
26 RePneu ${ }^{\circledR}$ Lungenvolumenreduktionsspiralen. Bedienungsanleitung. http://www.pneumrx.com/wp-content/uploads/2013/12/LBL0139DE.D-german-LVRC-IFU3.pdf

27 Magnussen H, Kramer MR, Kirsten AM et al. Effect of fissure integrity on lung volume reduction using a polymer sealant in advanced emphysema. Thorax 2012; 67: $302-308$

28 Iftikhar IH, McGuire FR, Musani AI. Efficacy of bronchoscopic lung volume reduction: a meta-analysis. Int J Chron Obstruct Pulmon Dis 2014; 9: 481-491

29 Schaefer H, Tasci S. Endoskopische Lungenvolumenreduktion beim Emphysem. Standortbestimmung nach einer Dekade. Pneumologie 2014; 68: $97-99$

30 Shah OL, Cardoso PFG, Cetti E. EASE trial study group. et al. Bronchoscopic lung volume reduction with Exhale airway stents for emphysema (EASE trial): randomized sham-controlled, multicentre trial. Lancet 2011; 378: $997-1005$

31 Miniati M, Monti S, Stolk J et al. Value of chest radiography in phenotyping chronic obstructive pulmonary disease. Eur Respir J 2008; 31: 509-515

32 Wielpütz M, Kauczor H. MRI of the lung: state of the art. Diagn Interv Radiol 2012; 18: 344 - 353

33 Ley-Zaporozhan J, Ley S, Eberhardt R et al. Visualization of morphological parenchymal changes in emphysema: comparison of different MRI sequences to 3D-HRCT. Eur J Radiol 2010; 73: 43-49

34 Biederer J, Heussel CP, Puderbach $M$ et al. Functional magnetic resonance imaging of the lung. Semin Respir Crit Care Med 2014; 35 $74-82$

35 Tetzlaff $R$, Eichinger M. Magnetresonanztomographie der Atembewegung und Lungenfunktion. Radiologe 2009; 49: 712 - 719

36 http://www.asconet.net/html/cosyconet

37 Newell JD Jr, Sieren J, Hoffman EA. Development of quantitative computed tomography lung protocols. J Thorac Imaging 2013; 28: 266-271

38 Zaporozhan J, Ley S, Weinheimer $O$ et al. Multi-detector CT of the chest: influence of dose onto quantitative evaluation of severe emphysema: a simulation study. J Comput Assist Tomogr 2006; 30: 460-468

39 Schroeder JD, McKenzie AS, Zach JA et al. Relationships between airflow obstruction and quantitative CT measurements of emphysema, air trapping, and airways in subjects with and without chronic obstructive pulmonary disease. Am J Roentgenol 2013; 201: W460 - W470

40 May MS, Eller A, Stahl C et al. Dose reduction in computed tomography of the chest: Image quality of iterative reconstructions at a $50 \%$ radiation dose compared to filtered back projection at a $100 \%$ radiation dose. Fortschr Röntgenstr 2014; 186: 576-578

41 Smith BM, Austin JH, Newell JD Jr et al. Pulmonary emphysema subtypes on computed tomography: the MESA COPD study. Am J Med 2014; 127: 94.e7-23

42 Lynch DA, Murphy JR, Crapo JD et al. COPDGene CT Workshop Group: A combined pulmonary-radiology workshop for visual evaluation of COPD: study design, chest CT findings and concordance with quantitative evaluation. COPD 2012; 9: 151-159

43 Gietema HA, Müller NL, Fauerbach PV et al. Quantifying the extent of emphysema: factors associated with radiologists' estimations and quantitative indices of emphysema severity using the ECLIPSE cohort. Acad Radiol 2011; 18: 661-671

44 Horger $M$, Grosse U, Hetzel J et al. Lung volume reduction by coils and valves and the role of CT-imaging. Fortschr Röntgenstr 2014; 186: 909-913

45 Heussel CP, Achenbach T, Buschsieweke C et al. Quantifizierung des Lungenemphysems in der Mehrschicht-CT mittels verschiedener Softwareverfahren. Fortschr Rontgenstr 2006; 178: 987 -998

46 Fiorelli A, Petrillo M, Vicidomini G et al. Quantitative assessment of emphysematous parenchyma using multidetector-row computed tomography in patients scheduled for endobronchial treatment with oneway valves. Interact Cardiovasc Thorac Surg 2014; 19: 246-255

47 Lynch DA, Al-Qaisi ML. Quantitative CT in COPD. J Thorac Imaging 2013; 28: $284-290$

48 Wielpütz MO, Bardarova D, Weinheimer O et al. Variation of densitometry on computed tomography in COPD - Influence of different software tools. PLoS One 2014; 9: e112898

49 Dirksen A, Piitulainen E, Parr DG et al. Exploring the role of CT densitometry: a randomised study of augmentation therapy in alpha1-antitrypsin deficiency. Eur Respir J 2009; 33: 1345 - 1353

50 Puderbach $M$, Hintze C, Ley S et al. MR imaging of the chest: a practical approach at 1.5T. Eur J Radiol 2007; 64: 345 - 355 
51 Coxson HO, Nasute Fauerbach PV, Storness-Bliss C et al. Computed tomography assessment of lung volume changes after bronchial valve treatment. Eur Respir J 2008; 32: 1443 - 1450

52 Voshaar TH. Collateral Ventilation. Pneumologie 2008; 62: 355-360

53 Takahasi K, Thompson B, Stanford W. Visualization of Normal Pulmonary Fissures on Sagittal Multiplanar Reconstruction MDCT. Am J Roentgenol 2006; 187: 389-397

54 Reymond E, Jankowski A, Pison C et al. Prediction of lobar collateral ventilation in 25 patients with severe emphysema by fissure analysis with CT. Am J Roentgenol 2013; 201: W571 -W575

55 Van Rikxoort EM, Goldin JG, Galperin-Aizenberg $M$ et al. A method for the automatic quantification of the completeness of pulmonary fissures: evaluation in a database of subjects with sever emphysema. Eur. Radiol 2012; 22: 302-309

$56 \mathrm{Pu}$ J, Wang $\mathrm{Z}, \mathrm{Gu} \mathrm{S}$ et al. Pulmonary fissure integrity and collateral ventilation in COPD patients. PLoS One 2014; 9: e96631
57 Hermanova Z, Ctvrtlik F, Herman M. Incomplete and accessory fissures of the lung evaluated by high-resolution computed tomography. Eur J Radiol 2013; 83: 595 - 599

58 Koenigkam-Santos $M$, de Paula WD, Owsijewitsch $M$ et al. Incomplete pulmonary fissures evaluated by volumetric thin-section CT: semiquantitative evaluation for small fissure gaps identification, description of prevalence and severity of fissural defects. Eur J Radiol 2013; 82: $2365-2370$

59 Herth FJ, Eberhardt R, Gompelmann D et al. Radiological and clinical outcomes of using Chartis ${ }^{\mathrm{TM}}$ to plan endobronchial valve treatment. Eur Respir J 2013; 41: 302-308

60 Davey C, Zoumot Z, Jordan S et al. Bronchoscopic lung volume reduction with endobronchial valves for patients with heterogeneous emphysema and intact interlobar fissures (The BeLieVeR-HIFi trial): study design and rationale. Thorax 2014; DOI: doi: 10.1136/thoraxjnl-2014205127 [Epub ahead of print] 